\title{
Effect of Workplace Noise and Light Conditions on Dentists' Quality of Life, Shiraz, 2013
}

\author{
Zamanian Z, PhD ${ }^{1}$, Nikeghbal K, Dentistry Student ${ }^{2}$, Ebrahimi H, BSc ${ }^{3}$, Purshahidi S, BSc ${ }^{3}$ \\ 1- Associate Prof., Dept of Occupational Health, School of Health, Shiraz University of Medical Sciences, Shiraz, Iran. \\ 2- Dentistry Student, School of Dentistry, Shiraz University of Medical Sciences, Shiraz, Iran. 3- BSc, Dept of Oral \\ Medicine, School of Dentistry, Shiraz University of Medical Sciences, Shiraz, Iran.
}

\begin{abstract}
Received: April 2014, Accepted: September 2014

Background: It has been prover that the prevalence of experiencing job related stress is very high among the dentists. This stress can be the result of factors such as poor lightening of dental office and noise. This stress can cause emotional distress and threaten dentists' physical health and affect the quality of their life. This study is conducted to determine dentists' professional quality of life and job-related stress and two important workplace factors that can affect them which are lighting and noise.

Materials and Methods: In this cross-sectional study the researchers visited the dental offices in Shiraz city and measured lighting and noise of the places, also dentist's quality of life and job stress were determined using McGill quality of life questionnaire and job-stress questionnaire.

Results: The relationship between quantitative variables was determined by using regression test and the multiple regression test was used for the modeling process. The average of local noise caused by dental drills and other parameters was 75.5 and 74.5 in public and private offices. In $2.2 \%$ of dental offices lightening condition was below the standard levels. Results show that $58.9 \%$ of dentists participating in this study experience good or fairly good quality of life.

Conclusion: The results suggest that workplace environmental situation and dentists' professional stress and quality of life are correlated. So adjusting effective workplace parameters to the standard levels can lead to increase in the dentists' quality of life.
\end{abstract}

Key words: Stress, Lighting, Noise, Clinic

\section{Introduction}

Studies conducted on various occupations have shown that job-related disorders are highly prevalent among the dentists. These stresses among the dentists lead to emotional distress, endanger the dentists' physical health, and reduce the efficiency in presenting high-quality services $(1,2)$. Researchers have revealed dentists to be stressful, nervous, and restless individuals. Difficulty of the relationship between the patient and the dentist, pressures resulting from visiting the patients, technical problems, relationships with the office personnel, and occupational dissatisfactions all lead to stress (3). The number of working hours per week is also directly related to the dentists' stress and mental distress. In general, more than one third of the dentists are obese (4). In addition, almost $60 \%$ of the dentists are nervous, rough, or depressed. Besides, $58 \%$ of them complaine about recurrent headaches, have sleeping disorders, and are always tired for no specific reasons (5). All of these are the result of the mental pressures of dentistry. Among the various dimensions of occupational stress, constant criticisms should be taken into account as

* Corresponding author: Kiana Nikeghbal, School of Dentistry, Shiraz University of Medical Sciences, Shiraz, Iran.

Email: nikeghbalk@sums.ac.ir 
well because dentists are considered as the creators of pain and suffering (6).

However, nowadays, a novel concept of occupational stresses; i.e., working life quality, has been considered by the managers $(7,8)$. Working life quality is a comprehensive program which is devoted to improvement of the staff's satisfaction (9). In fact, working life quality is essential for attraction and maintenance of the staff in all types of organizations (10). Working life quality is a set of actual working conditions in an organization, including salary and benefits, welfare facilities, health and safety considerations, cooperation in decision making, management method, and variety and richness of the occupations. Working life quality particularly expresses the staff's attitude toward their occupation $(11,12)$. The results of the study by Mehrstedt et al. (13) showed that as the staff's salary and benefit increased, their working life quality improved, as well (14).

Life quality is a multi-dimensional concept which is defined by World Health Organization as an individual's perception of one's life considering the culture and value system and their relationship with goals, expectations, interests, standards, and life experiences. This broad concept in fact affects the individuals' physical health, mental status, independence, social relationships, and personal beliefs (15).

Quality of life as a health concept has various characteristics, such as being multidimensional, dynamic, and subjective, and involves various physical, mental, and social dimensions. Relationship is one of the major dimensions of maintenance and improvement of life quality. Activities as well as the relationships related to performance of occupational duties can affect the individuals' quality of life. Dentistry is one of most important occupations in the field of health
(16). Brancatisano et al. (17) conducted a research on a number of women who had long been involved in hand work in low light working places. That study which was performed in 2008 by Brancatisano showed that these women suffered from a kind of depression resulting from improper light.

Furthermore, noise causes a large number of problems in the workplace. Noise not only has negative impacts on the auditory system, but it may also cause hypertension, cardiovascular problems, muscular tension, peptic ulcer, nerves stimulation, anxiety, sleeping disorders, and mental problems, including effects on conversation and efficiency, reclusiveness, resentment, depression, and absence from work (18).

Considering the importance of the issue, the present study aims to investigate noise, light and occupational stress in dentistry in order to evaluate the dentists' quality of life.

\section{Materials and Methods}

The present cross-sectional study was conducted on 200 dentists working in dentistry clinics who were entered into the study randomly. The dentists' workplace light was quantitatively measured using luxmeter device. The workplace noise was also quantitatively measured using sound level meter. In addition, the dentists' quality of life was assessed through McGill quality of life questionnaire (19). This questionnaire differs from most others in three ways: the existential domain is measured; the physical domain is important but not predominant; positive contributions to quality of life are measured (20). The MQOL-CSF consists of only 8 (1 global QoL item, 3 physical symptom items, 2 psychological items and 2 existential items) out of the total 17 items in the original instrument (21).

Besides, the rate of stress was evaluated using stress assessment questionnaire whose 
reliability and validity have been approved in various studies $(22,23)$. The questionnaires' data were then presented quantitatively. Afterwards, the values obtained from luxmeter and sound level meter were compared to the values obtained from the questionnaires. Finally, the data were entered into the SPSS statistical software (v. 15) and multiple regression test was used for modeling. The study researchers also considered the ethical principles; including asking for the dentists' permission, explaining the study objectives, and obtaining written informed consents.

\section{Results}

The findings of the present study showed that $72(71 \%)$ of the dentists were male and $18 \%$ were single. In addition, 127(63.5\%) of the study subjects had general education, while $73(36.5 \%)$ were specialists. Besides, $29(14.5 \%), 100(50 \%)$, and $70(35 \%)$ of the participants worked in morning, evening, and both shifts, respectively. Also, 137(68.5\%) worked in private clinics. Moreover, $23(11.5 \%)$ of the subjects suffered from hypertension, 18(9\%) had backache and cervical osteoarthritis, 14(7\%) had cardiovascular disorders, and 12(6\%) complained about headache, gastrointestinal disorders, asthma, and skin disorders.

The mean of dental drill noise was 75.5 and $77.4 \mathrm{~dB}$ in public and private clinics, respectively. In addition, the mean of local light on dental units was between 500 and 1000 lux and their lighting were below the standard level in $2.2 \%$ of the clinics.

Table 1: Relationship between the quantitative variables and quality of life in dentists $(n=200)$

\begin{tabular}{lccccc}
\hline \multicolumn{1}{c}{ Variables } & Min & Max & SD $\pm \boldsymbol{\mu}$ & $\mathbf{P}_{\text {val }}$ & $\begin{array}{c}\text { Pearson's } \\
\text { Correlations }\end{array}$ \\
\hline Noise Level pressure(dB) & 63 & 92 & $76.7 \pm 3.6$ & 0.2 & 0.1 \\
\hline Light intensity(lux) & 500 & 1000 & $742.2 \pm 70.3$ & $0.006^{*}$ & 0.4 \\
\hline Age(year) & 26 & 68 & $42.3 \pm 10.5$ & $0.007^{*}$ & 0.3 \\
\hline working experience(year) & 2 & 44 & $15.5 \pm 10.1$ & $0.01^{*}$ & 0.3 \\
\hline working hours per day & 3 & 10 & $5.3 \pm 1.9$ & $0.02^{*}$ & 0.1 \\
\hline working hours per week & 3 & 70 & $28.1 \pm 12.8$ & 0.07 & 0.2 \\
\hline number of daily & 2 & 30 & $8 \pm 5$ & $0.01^{*}$ & 0.1 \\
admissions & & & & & \\
\hline
\end{tabular}

$* \mathrm{P}<0.05$

Statistical indexes of quantitative variables, such as age, working hours per day and week, working experience, and number of daily admissions, are presented in table 1 also it shows the relationship between the quantitative variables and quality of life. Mean and standard deviation of some indicators of quality of the dentists' life quality are shown in table 2 . Table 3 presents the relationship between sex, marital status, having children, level of education and quality of life. The relationship between various diseases and life quality, noise level, and light intensity is presented in Table 4. 
Table 2: Mean and standard deviation of some quality of life parameters in dentists $(n=200)$

\begin{tabular}{lccc}
\hline \multicolumn{1}{c}{ Variables } & Min & Max & SD $\pm \boldsymbol{\mu}$ \\
\hline physical performance & 47 & 130 & $83.31 \pm 30.26$ \\
\hline physical impairment & 27 & 102 & $69.32 \pm 31.57$ \\
\hline physical pain & 0 & 80 & $34.76 \pm 31.35$ \\
\hline general health & 12 & 70 & $36.29 \pm 18.90$ \\
\hline vitality & 32 & 83 & $52.94 \pm 15.53$ \\
\hline social function & 26 & 75 & $47.75 \pm 13.87$ \\
\hline emotional problem & 16 & 94 & $57.35 \pm 35.42$ \\
\hline psychological health & 31 & 67 & $46.54 \pm 8.67$ \\
\hline quality of life & 39 & 71 & $53.73 \pm 7.30$ \\
\hline
\end{tabular}

Table 3: Relationship between some demographic characteristics and quality of life in dentists (n=200)

\begin{tabular}{lccc}
\hline \multicolumn{2}{c}{ Variables } & Number(\%) & P $_{\text {val }}$ \\
\hline Sex & & & 0.06 \\
& Female & $58(29)$ & \\
\cline { 2 - 3 } & Mail & $142(71)$ & \multirow{2}{*}{0.06} \\
\hline marital status & married & $164(82)$ & \\
\cline { 2 - 3 } & Single & $36(18)$ & 0.09 \\
\hline have children & Yes & $134(67)$ & 0.5 \\
\cline { 2 - 3 } & No & $66(33)$ & \\
\cline { 2 - 3 } & General of education & $127(63.5)$ & \\
\cline { 2 - 3 } & Specialist & $73(36.5)$ & \\
\hline
\end{tabular}

The findings of the present study showed that $118(59 \%)$ of the dentists reported their life quality as desirable and almost desirable. On the other hand, $85(42.5 \%)$ considered their life quality to be undesirable. Regarding the dimensions of life quality, nearly $50 \%$ of the study subjects rated their physical, social, economic, mental, sleeping and rest, and general health dimensions of life quality as desirable and almost desirable, while the remaining $100(50 \%)$ considered them as undesirable. Overall, the working life quality of most of the study subjects $162(81 \%)$ was at an average level. Working life quality revealed a statistically significant relationship with marital status, but a negative correlation with working hours per week $(\mathrm{P}<0.01)$. Moreover, a positive correlation was observed among most of the dimensions of working life quality.

The findings of the current study showed a direct relationship between workplace light and life quality $(\mathrm{P}=0.006)$. In addition, a significant reverse relationship was found between life quality and age as well as working experience $(\mathrm{P}=0.01, \mathrm{P}=0.02)$.

Significant reverse relationships were also observed between life quality and number of 
daily admissions as well as number of working hours per day. According to the study results, as the workplace light, age, and working experience increased, the working life quality increased, as well. Moreover, a decrease in the number of daily admissions and working hours per day increased the working life quality. Reduction of working hours per week also increased the working life quality, but the relationship was not statistically significant.

Table 4: Relationship between various diseases in dentists and quality of life, noise level, light intensity $(\mathrm{n}=\mathbf{2 0 0})$

\begin{tabular}{lcccc}
\hline \multicolumn{1}{c}{ Variables } & Number (\%) & $\begin{array}{c}\text { Quality of } \\
\text { Life }\end{array}$ & $\begin{array}{c}\text { Noise Level } \\
\text { pressure }\end{array}$ & $\begin{array}{c}\text { Light } \\
\text { intensity }\end{array}$ \\
\hline Backache & $38(19)$ & $0.006^{*}$ & 0.6 & 0.8 \\
\hline Neck ache & $38(19)$ & $0.001^{*}$ & 0.2 & 0.8 \\
\hline $\begin{array}{l}\text { Musculoskeletal } \\
\text { Disorders }\end{array}$ & $51(25.5)$ & $0.005^{*}$ & 0.1 & 0.3 \\
\hline $\begin{array}{l}\text { Psychological } \\
\text { disorders }\end{array}$ & $62(31)$ & $0.03^{*}$ & $0.04^{*}$ & $0.02^{*}$ \\
\hline $\begin{array}{l}\text { High blood } \\
\text { pressure }\end{array}$ & $23(11.5)$ & $0.02^{*}$ & 0.5 & $0.03^{*}$ \\
\hline $\begin{array}{l}\text { Gastrointestinal } \\
\text { disorders }\end{array}$ & $9(4.5)$ & & & $0.04^{*}$ \\
\hline$*$ P <0.05 & & & & \\
\hline
\end{tabular}

\section{Discussion}

Noise can have a more global effect on human physiology and act upon multiple non-auditory systems such as cardiovascular, neuroendocrine, and psychological aspects (24). Psychological and physiological nonauditory effects of noise result in detrimental health consequences and a decreased quality of life that also shows in this study $(25,26)$.

Regarding the dimensions of life quality, nearly $100(50 \%)$ of the study subjects rated their physical, social, economic, mental and sleeping and rest, and general health dimensions of life quality as desirable and almost desirable, while the remaining $50 \%$ considered them as undesirable. The results of the study by Janse et al. (27) also showed that life quality ranged from average to almost desirable in all the dimensions. In the present study, the male subjects' life quality was significantly better than that of the females, which is in contrast to the studies done by Dracup et al. (28) and Testa et al. (29) showing no significant differences between the two sexes. The difference between the results of other studies and those of the current study might be due to the high workload on Iranian female dentists resulting from doing the household chores and taking care of the children. On the other hand, Sut et al. (30) showed that the life quality of male subjects was significantly lower than that of the females.

In this study, no significant difference was found between married and single subjects regarding life quality total score. However, the physical function score of the married subjects was significantly higher than that of the single ones, which is in contrast with the findings of the study by Goker et al. (31). 
The study results revealed no significant relationship between the level of education and quality of life, which is in agreement with the study by Kempen et al. (32). However, this finding is inconsistent with the results of the study by Klepac and Vladimir (33) which showed a significant increase in the quality of life by the increase in the level of education.

Investigation of the workplace condition showed that the dental turbine's noise level was $94.4 \mathrm{~dB}$. The mean of turbine's noise level in both public and private clinics was above Iran's standard level (85 dB) (34). Besides, the local light intensity of the dental unit was below the standard level (500-1000 lux) (34) in all the clinics.

\section{Conclusion}

This study shows more evidence to highlight noise as an unwanted occupational pollutant which has global implications. In our industrialized society, a significant population is exposed to noise on a daily basis with its resultant health effects, and subsequent substantial economic burden. This results in significant deterioration in quality of life in that it disrupts cardiovascular, gastrointestinal, respiratory system, skin and has many non-auditory deleterious health effects.

However, providing trainings regarding workplace control and management can considerably reduce the destructive effects of this psychological disorder and increase the quality of life.

Considering the fact that training the dentists is quite costly for the government, mental health of this group of the society is of great importance. Therefore, the expenses of implementing the research results and the time and human resources spent in order to reach this aim are quite negligible compared to its advantages. Of course, further studies are required to be conducted on the issue. It should be mentioned that the study results might be affected by the type of instrument and environment; therefore, performing further studies may require specific instruments.

\section{Acknowledgements}

This study was part of a General Dentistry thesis of Kiana Nikeghbal supported by Shiraz University of Medical Sciences (no: 1434).

Conflict of interests: Non declared

\section{References:}

1. Mead MN. The sound behind heart effects. Environ Health Perspect 2007; 115(11):A536-7.

2. Myers HL, Myers LB. It's difficult being a dentist: stress and health in the general dental practitioner. Br Dent J 2004; 197(2):89-93.

3. Osborne D, Croucher R. Levels of burnout in general dental practitioners in the south-east of England. Br Dent J 1994; 177(10):372-7.

4. Ayers KM, Thomson WM, Newton JT, Rich AM. Job stressors of New Zealand dentists and their coping strategies. Occup Med (Lond) 2008; 58(4):275-81.

5. Abu-Ghazaleh SB, Rajab LD, Sonbol HN. Psychological stress among dental students at the University of Jordan. J Dent Educ 2011; 75(8):1107-14.

6. Cooper CL, Mallinger $\mathrm{M}$, Khan $\mathrm{R}$. Identifying sources of occupational stress among dentists. J Occup Psychol 1978; 51(3): 227-34.

7. Yee T, Crawford L, Harber P. Work environment of dental hygienists. J Occup Environ Med 2005; 47(6):633-9.

8. Molaie B, Mohamadi M, Habibi A, Zamanzadeh V, Dadkhah B, Molavi P, et al. A Study of job stress and its related causes among employed women in Ardabil City. 
Journal Of Ardabil University Of Medical Sciences 2011; 11(1): 76-85.

9. Akerstedt T. Psychological and psychophysiological effects of shift work. Scand J Work Environ Health 1990; 16(1):67-73.

10. Gan WQ, Davies HW, Demers PA. Exposure to occupational noise and cardiovascular disease in the United States: the National Health and Nutrition Examination Survey 1999-2004. Occup Environ Med 2011; 68(3):183-90.

11. Stallen PJ. A theoretical framework for environmental noise annoyance. Noise Health 1999; 1(3):69-80.

12. Zare M, Abedini K, Rahiminejad M, Halvani $\mathrm{GH}$, Barkhordari A, Valipour E. Influence of aircraft noise on hypertension in airport staff. Journal of Babol University of Medical Sciences 2009; 10(6):54-61.

13. Mehrstedt M, Tönnies S, Eisentraut I. Dental fears, health status, and quality of life. Anesth Prog 2004; 51(3):90-4.

14. Jurkat H, Hofer S, Richter L, Cramer M, Vetter A. Quality of life, stress management and health promotion in medical and dental students. A comparative study. Dtsch Med Wochenschr 2011; 136(23):1245-50.

15. Feu D, Cardoso C, Quintão A, Augusto J, Miguel M. Quality of life instruments and their role in orthodontics. Dental Press J Orthod 2010; 15(6): 61-70.

16. Allen PF. Assessment of oral health related quality of life. Health Qual Life Outcomes 2003; $1: 40$

17. Brancatisano A, Wahlroos S, Brancatisano R. Improvement in comorbid illness after placement of the Swedish Adjustable Gastric Band. Surg Obes Relat Dis 2008; 4(3):S3946.

18. Stansfeld SA, Matheson MP. Noise pollution: Non-auditory effects on health. $\mathrm{Br}$ Med Bull 2003; 68(1):243-57.

19. Cohen SR, Mount BM, Tomas JJ, Lauren LF. Existential well-being is an important determinant of quality of life. Evidence from the McGill Quality of Life Questionnaire. Cancer 1996; 77(3):576-86.

20. Cohen SR, Mount BM, Strobel MG, Bui F. The McGill Quality of Life Questionnaire: a measure of quality of life appropriate for people with advanced disease. A preliminary study of validity and acceptability. Palliat Med 1995; 9(3):207-19.

21. Lua PL, Salek S, Finlay I, Lloyd-Richards C. The feasibility, reliability and validity of the McGill Quality of Life Questionnaire-Cardiff Short Form (MQOL-CSF) in palliative care population. Qual Life Res 2005; 14(7):166981.

22. Shahidi J, Khodabakhshi R, Gohari MR, Yahyazadeh H, Shahidi N. McGill Quality of Life Questionnaire: reliability and validity of the Persian version in Iranian patients with advanced cancer. J Palliat Med 2008; 11(4):621-6.

23. Bahrami N, Moradi M, Soleimani MA, Kalantari Z, Hosseini F. Death Anxiety and its Relationship with quality of life in Women with Cancer. Iran Journal of Nursing 2013; 26(82): 51-61.

24. Passchier-Vermeer W, Passchier WF. Noise exposure and public health. Environ Health Perspect 2000; 108(1):123-31.

25. Evans GW, Lepore SJ. Nonauditory effects of noise on children: A critical review. Children's Environments 1993; 10(1): 31-51.

26. Poulton E. A new look at the effects of noise: A rejoinder. psychology bulletin 1978; 85(5):1068-79.

27. Janse AJ, Gemke RJ, Uiterwaal CS, van der Tweel I, Kimpen JL, Sinnema G. Quality of life: patients and doctors don't always agree: a meta-analysis. J Clin Epidemiol 2004; 57(7):653-61.

28. Dracup K, Walden JA, Stevenson LW, Brecht ML. Quality of life in patients with advanced heart failure. J Heart Lung Transplant 1992; 11(2 Pt 1):273-9.

29. Testa MA, Simonson DC. Assessment of quality-of-life outcomes. N Engl J Med 1996; 334(13):835-40.

30. Sut KH, Kaplan PB, Sut N, Tekbas S. The assessment of quality of life in female Turkish patients with overactive bladder. Int J Nurs Pract 2012; 18(1):20-7.

31. Goker A, Guvenal T, Yanikkerem E, Turhan A, Koyuncu FM. Quality of Life in women with gynecologic cancer in Turkey. Asian Pac J Cancer Prev 2011; 12(11):3121-8.

32. Kempen GI, Ormel J, Brilman EI, Relyveld J. Adaptive responses among Dutch elderly: the impact of eight chronic medical conditions on health-related quality of life. Am J Public Health 1997; 87(1):38-44.

33. Klepac N, Trkulia V. Education effect on depression and quality of life in nondemented parkinson's disease pationts. J Neuropsychiatry Clin Neurosci 2009; 21(3):314-22.

34. Gholmohammadi R (2011). Occupational Exposure Limits(OEL). $3^{\text {th }}$ ed. Tehran: Tehran University of Medical Sciences Institute for Environmental Research. P16972. 